\title{
Study on Size Distribution and Flow Characteristics of Condensed Products in Solid Rocket Motor
}

\author{
Mengying Liu, ${ }^{1,2}$ Zhu Liu, ${ }^{3}$ Shipeng Li $\mathbb{C}^{1},{ }^{1}$ Wenhao Yu, ${ }^{1}$ Jian Cao, ${ }^{4}$ and Ningfei Wang ${ }^{1}$ \\ ${ }^{1}$ Beijing Institute of Technology, Beijing, China \\ ${ }^{2}$ Nanjing University of Aeronautics and Astronautics, Nanjing, China \\ ${ }^{3}$ Science and Technology on Space Physics Laboratory, Beijing, China \\ ${ }^{4}$ China Ship Scientific Research Center, Wuxi, China \\ Correspondence should be addressed to Shipeng Li; lsp@bit.edu.cn
}

Received 14 May 2021; Accepted 14 July 2021; Published 5 August 2021

Academic Editor: Marco Pizzarelli

Copyright (c) 2021 Mengying Liu et al. This is an open access article distributed under the Creative Commons Attribution License, which permits unrestricted use, distribution, and reproduction in any medium, provided the original work is properly cited.

\begin{abstract}
The size distribution of condensed products during the combustion of aluminized propellants and flow characteristics of the gassolid two-phase flow in solid rocket motor were studied in this paper. Firstly, based on the laser scattering technology, an online detection system for condensed products in plume was established, and the size detection of condensed products in the plume of solid rocket motor is carried out. Secondly, a numerical model of two-phase flow in solid rocket motor is established by combining the real size distribution of products in the plume with discrete phase model through the Rosin-Rammler distribution function. Besides, numerical simulation research is carried out under the same experimental conditions, focusing on the influence of condensed products with real size on the characteristics of solid rocket motor. The results show that the innovation measurement system can be used to obtain the size distribution characteristic of condensed products in the plume. At the particle size of stable stage, the mean size, $D_{v}(50)$, is $104 \mu \mathrm{m}$, which is the smallest among all stages. It is also suggested that condensed products at the end stage have the most impact on the flow behavior in solid rocket motor, in that the shock structure, Mach number, and temperature distribution in the near field of plume are significantly changed.
\end{abstract}

\section{Introduction}

The application of energetic metal materials in solid propellants has become one of the current research hotspots. Aluminum particles have been widely used in solid propellants because of their low cost, less chemical reaction during processing and storage, nontoxic combustion products, and significantly improved specific impulse. The content of aluminum particles in solid propellants is usually in the range of 10\% 20\% [1-5]. The combustion and flow process of condensed products in a typical solid rocket motor (SRM) can be divided into four stages as shown in Figure 1: the initial aluminum particles $\left(\mathrm{Al}^{0}\right)$ in propellant, the initial agglomerates near the burning surface, the condensed products in the combustion chamber and nozzle, and the final agglomerates in the plume. The condensed products after leaving burning surface not only affect the propulsion efficiency, combustion stability, and infrared radiation of the system but also bring two-phase flow loss, erosion combustion, and particle deposition. The size of condensed products has a key impact on the performance of propulsion system. Therefore, it is of great scientific and engineering significance to obtain real size distribution of condensed products in the plume at different combustion stages for simulating the performance of SRMs.

The combustion and flow process of condensed products in plume involves complex physical and chemical changes. Many scholars have adopted theoretical modeling, experimental test, numerical simulation, and other methods to analyze the size of condensed products during the process of combustion. Beckstead et al. [6-8] comprehensively considered the effects of oxidant types and temperature on the 


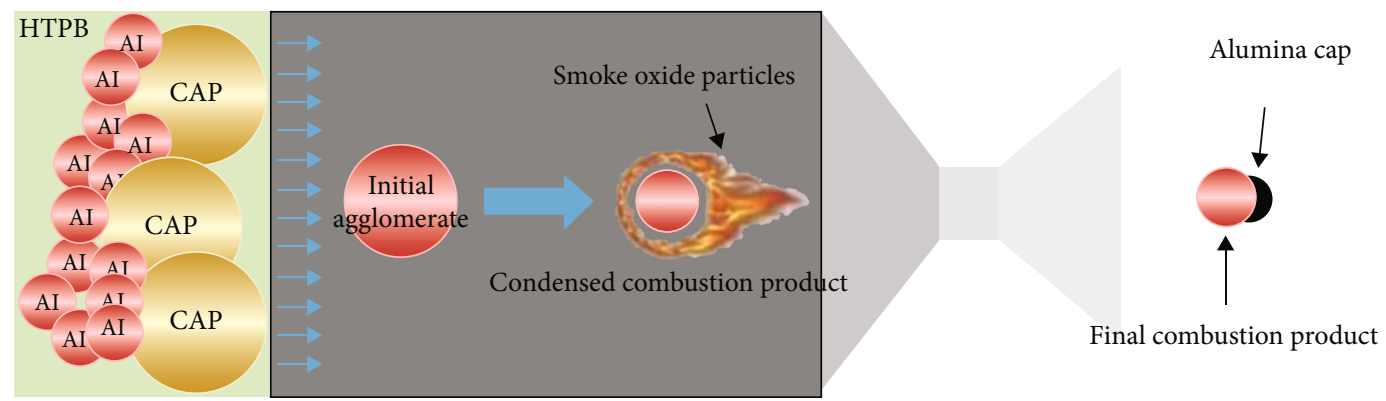

FIgURE 1: Combustion and motion of aluminum in a SRM.

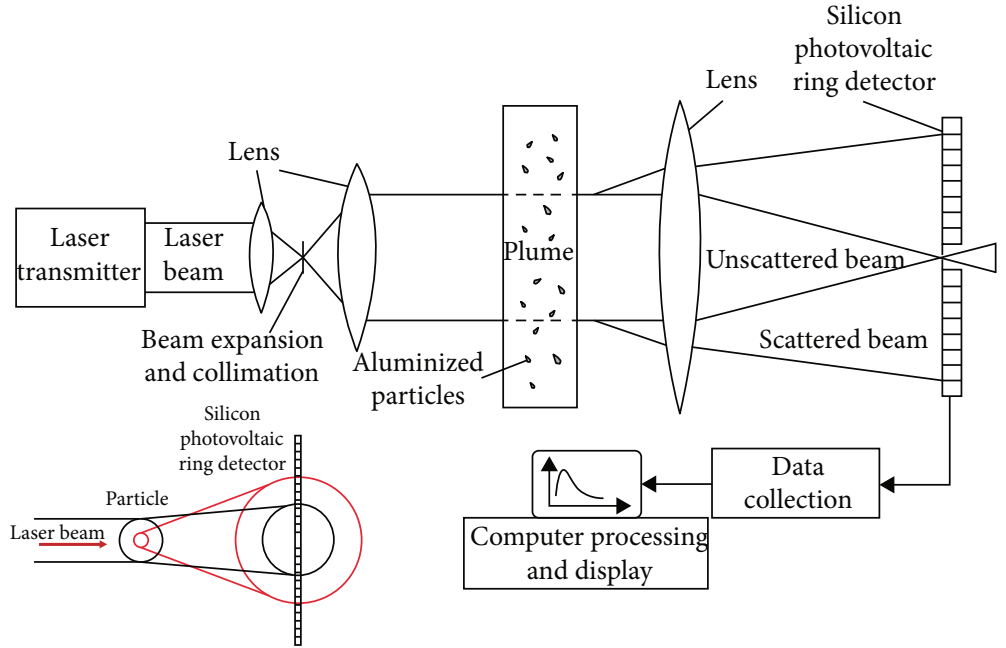

Figure 2: Particle size analysis based on the Mie theory.

combustion process of aluminum particles, and proposed a $d^{n}$ law of combustion time of aluminum particles in the range of 10-100 $\mu \mathrm{m}$. Babuk et al. [9], Melcher et al. [10], Zarko and Glotov [11], and Ao et al. [12, 13] have successively analyzed the physical and chemical processes involved in the combustion and agglomeration of aluminum particles in aluminized propellants by using sampling methods and high-speed photography technology, mainly including the gas phase combustion of metals, the chemical reaction between $\mathrm{Al}$ and $\mathrm{Al}_{2} \mathrm{O}_{3}$, and the change of particle structure and the fusion between particles. At the same time, an empirical prediction model for average diameter of condensed products in plume was established, but none of these works were carried out in the actual SRM conditions. The influence of AP size on the agglomeration process of aluminum particles was analyzed by means of windowing engine and SEM, XPS, and XRD by DeLuca [14]. Hovland [5], Laredo et al. [15], and Haiqing [16] have used noncontact measurement technology to promote the application and development of laser forward scattering technology in the field of size distribution detection in plume. Weilun et al. [17] have used laser forward scattering technology to study the influence of propellant components on the particle size of condensed products. The above research has laid a foundation for understanding the working characteristics of SRMs, but the research on size distribution of condensed products in the high-temperature and highspeed gas plume at actual working condition of SRM is still lacking, which cannot provide data support for the performance simulation of SRM. At present, uniform size [18] or semiempirical formula [19] is often used to describe the distribution of solid particles in combustion chamber and plume when simulation, but this method cannot describe the change of solid particle size along space and time, which affects the accuracy and reliability of the model.

In this paper, the size distribution of condensed products during the combustion of aluminized propellants and flow characteristics of gas-solid two-phase flow in solid rocket motor were studied. Firstly, based on the laser scattering technology, an online detection system for condensed products in plume was established; secondly, the real size distribution of condensed products was combined with discrete phase model by the Rosin-Rammler (R-R) distribution function, and the gas-solid two-phase flow numerical model of SRM was established. The simulation was carried out under the same test conditions, and the influence of real products on the flow characteristics of SRM was analyzed.

\section{Experimental Principle and Systems}

2.1. Principle of Laser Measurement. With the development of scattering theory and computer data processing ability, the Mie theory has been widely used in the field of size measurement. When a laser beam, with wavelength $\lambda$ and incident light $I_{0}$, irradiates on the surface of spherical particle 
with equivalent diameter $D$, the forward light intensity distribution produced by particle scattering can be obtained from Equation (1) [20-23]:

$$
I_{s c a}=\frac{\lambda^{2}}{4 \pi^{2} r^{2}} I_{0}\left[i_{1}(\theta, \alpha, m) \cos ^{2} \varphi+i_{2}(\theta, \alpha, m) \sin ^{2} \varphi\right]
$$

where $\theta$ is scattering angle, $\alpha=\pi D / \lambda$ is dimensionless size parameter, $m=n-i \eta$ is refractive index of the particle relative to the surrounding medium, $r$ is the distance from the particle to the observation plane, $\varphi$ is the angle between the electric vector of the incident light and the scattering plane, and $i_{1}$ and $i_{2}$ are the scattering intensity function components perpendicular to and parallel to the scattering plane, respectively.

By integrating Equation (1) on each torus, the scattering energy of particles on the $n$th ring of the multielement photodetector can be calculated when the Mie scattering occurs:

$$
E_{n}=C^{\prime} \sum_{i} \frac{W_{i}}{D_{i}^{3}} \int_{\theta_{n, 1}}^{\theta_{n, 2}}\left(i_{1}+i_{2}\right) \sin \theta d \theta=C^{\prime} \sum_{i} t_{n, i} W_{i}
$$

where $\theta_{n, 1}=\arctan \left(r_{n, 1} / f\right), \theta_{n, 2}=\arctan \left(r_{n, 2} / f\right)$, and $C^{\prime}$ is a constant. Equation (2) can also be written in matrix form:

$$
\mathbf{E}=\mathbf{T} \times \mathbf{W}
$$

Equation (3) establishes the corresponding relationship between the scattered light energy and the particle size. If the particle size distribution $\left(W_{1}, W_{2}, \ldots, W_{k}\right)$ is known, the scattered light energy $\left(E_{1}, E_{2}, \ldots, E_{M}\right)$ received by each detection ring can be obtained. On the contrary, if the scattered light energy distribution of a particle on each detection ring is known, the particle size distribution of the corresponding particle can also be calculated by Equation (3).

The basic principle of laser size detection system based on the Mie theory is shown in Figure 2, which is mainly composed of laser transmitter, the Fourier lens, silicon photovoltaic ring detector, data acquisition, and processing system. The particles with different sizes in the plume make the laser beam produce different scattering angles (the scattering angle of small particles is larger, and the scattering angle of large particles is smaller). After passing through the Fourier lens, the laser beam is transmitted into the array detector. The data acquisition and processing system obtains the particle size distribution in the plume by solving Equation (3).

In the laser size detection system used in this paper, there are 12 detection rings to receive the scattered light energy. Besides, the power of laser beam can reach $1 \mathrm{~mW}$, the wavelength is $670 \mathrm{~nm}$, and the diameter of laser beam is $12 \mathrm{~mm}$. The sampling frequency of the laser size measurement system can reach $1 \mathrm{kHz}$. Meanwhile, in the laser size detection system, the particle size is widely tested, and particles in the diameter range of $0.287-1000 \mu \mathrm{m}$ can be measured.

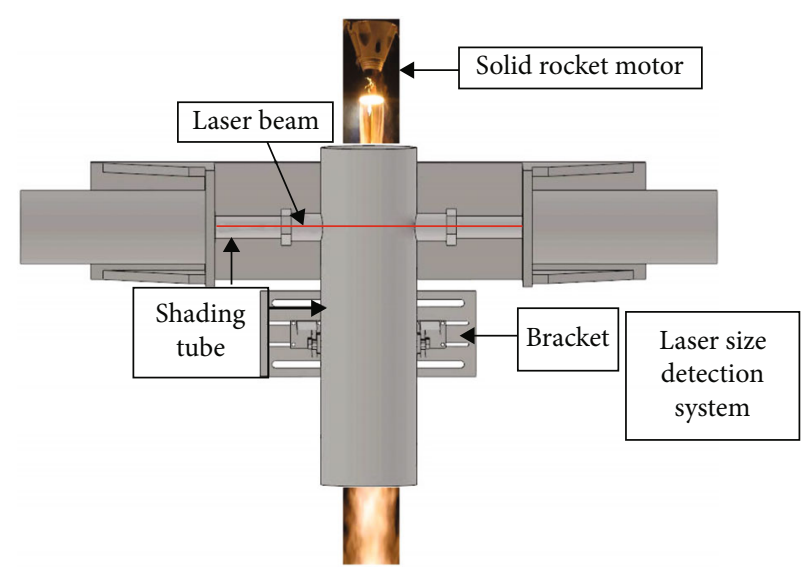

FIgURE 3: Online detection system of condensed products in the plume.

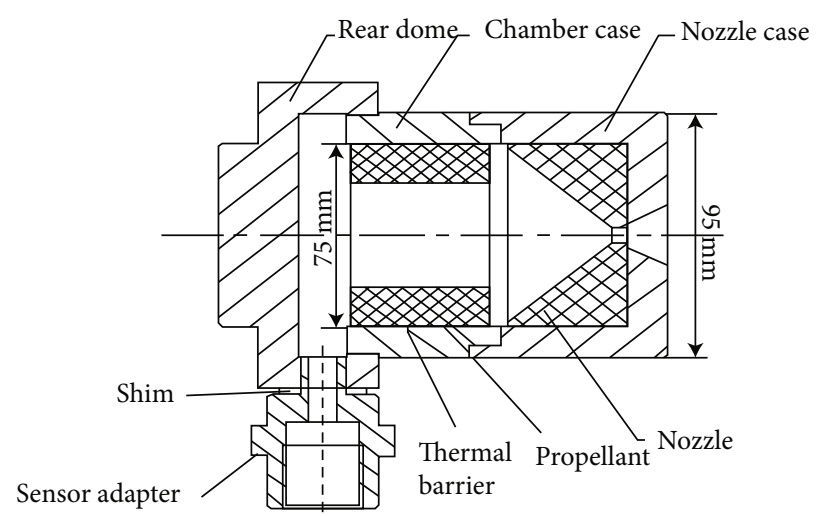

FIGURE 4: Structure of tested solid rocket motor.

TABLE 1: Formulation of the propellant.

\begin{tabular}{lccc}
\hline $\mathrm{Al}(\mathrm{wt} \%)$ & $\mathrm{HTPB}(\mathrm{wt} \%)$ & $\mathrm{AP}(\mathrm{wt} \%)$ & $D_{\mathrm{Al}}(\mu \mathrm{m})$ \\
\hline 18 & 15 & 67 & 5 \\
\hline
\end{tabular}

Owing to the irregular shape of the condensed products, the size was characterized by the equiarea circular diameter (CE diameter); in other words, the two-dimensional irregular shape of the condensed product in the image was converted into a circle with an equal area, and the diameter of this circle was recorded as the final size of the condensed product. For each time or a certain time period, the diameter $\left(D_{v}(10)\right.$, $D_{v}(50)$, and $\left.D_{v}(90)\right)$ was used to characterize the average size of the condensed-phase product group:

$D_{v}(10)$ means $10 \%$ of particle size in the plume is lower than this value, while the other $90 \%$ is larger than the value.

$D_{v}(50)$ means $50 \%$ of particle size in the plume is lower than this value, while the other $50 \%$ is larger than the value, and this is the median size.

$D_{v}(90)$ means $90 \%$ of the particle size in the plume is lower than this value, while the other $10 \%$ is larger than the value.

2.2. Online Detection System. An online measurement system for condensed products, which is in the high-temperature and high-pressure environment, was designed based on the laser 


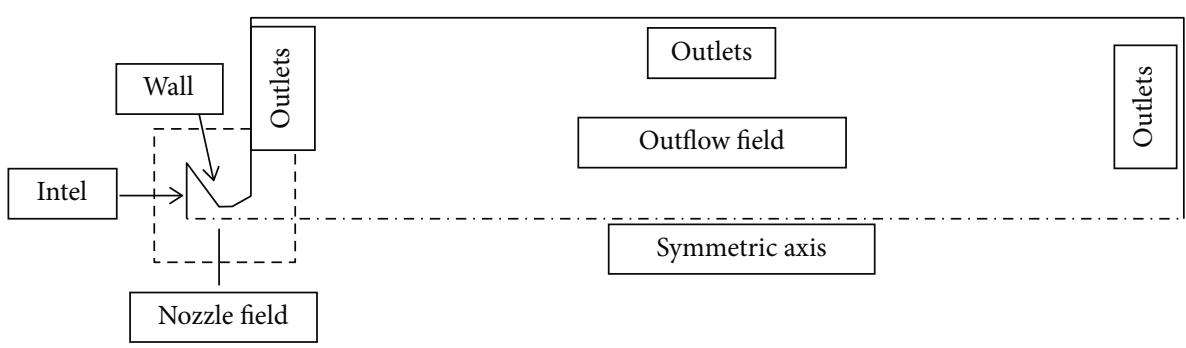

(a) Computational domain and boundary conditions

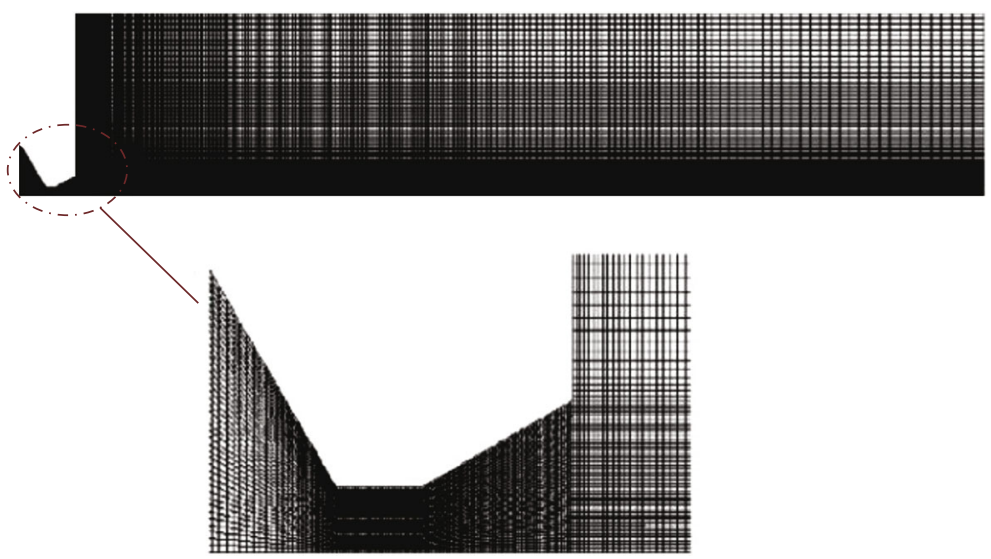

(b) Grid

FIGURE 5: Computational domain model and grid. (a) Computational domain and boundary conditions. (b) Grid.

measurement system to detect the real-time size distribution. The online measurement system mainly includes laser size detection system, solid rocket motor, protective gas system, data acquisition system, and auxiliary measurement device. The system composition is shown in Figure 3. Among them, the protective gas system was used to protect the optical devices at the transmitting and receiving ends of the online measurement system to avoid the damage of high-temperature and highspeed plume to the instrument. The auxiliary measuring device is mainly composed of adjustable bracket and shading tube, which is used to shield the interference of external environment (such as light and dust) during the process of measurement. Therefore, in order to obtain the convincing data, the influence of shading tube on the condensed products in the plume should be avoided, so the inner diameter of shading tube should be larger than that of the core area of the whole plume.

The structure of tested SRM is shown in Figure 4. The design pressure in the chamber on working condition is $6 \mathrm{MPa}$, the inner diameter of the chamber is $75 \mathrm{~mm}$, and the length of the chamber is $130 \mathrm{~mm}$. The charge form of the propellant is tubular, and the thickness is $10 \mathrm{~mm}$. Besides, the end surface is not covered, and the inner hole is used for combustion. Black powder is used for ignition. In the test, the three-component HTPB aluminized propellant is applied, including $18 \%$ of aluminum, $15 \%$ of $\mathrm{HTPB}$, and $67 \%$ of AP, and the diameter of virgin aluminum particle is $5 \mu \mathrm{m}$. The specific formula is listed in Table 1.

\section{Mathematical and Physical Models}

3.1. Control Equations and Numerical Methods. The internal flow in the chamber and plume is a complex gas-solid two-
TABle 2: Parameters of gas performance.

\begin{tabular}{lcccc}
\hline $\begin{array}{l}C_{p} \\
(\mathrm{~J} /(\mathrm{kg} \cdot \mathrm{K}))\end{array}$ & $\begin{array}{c}\lambda \\
(\mathrm{W} /(\mathrm{m} \cdot \mathrm{K}))\end{array}$ & $\begin{array}{c}T \\
(\mathrm{~K})\end{array}$ & $\begin{array}{c}\text { Mole fraction of } \\
\mathrm{Al}_{2} \mathrm{O}_{3}(\%)\end{array}$ & $\begin{array}{c}\text { Molar mass of } \\
\text { gas }(\mathrm{g} / \mathrm{mol})\end{array}$ \\
\hline 2020 & 0.4090 & 3510 & 8 & 28.789 \\
\hline
\end{tabular}

phase flow system, and its main mechanical effect is a momentum transfer between high-speed gas and solid particles. Therefore, the numerical simulation can be simplified, ignoring the mass transfer between gas phase and particle phase. The gas phase adopts the ideal gas model, but some factors such as chemical reaction, gravity, radiation heat transfer, and the influence of afterburning are ignored, and the influence of particle phase on temperature and velocity of gas phase is focused on. It is considered that the gas phase (gas) is continuous and the particle phase (condensed products) is discrete. The Navier-Stokes equations are used as the control equations, and the discrete phase model (DPM) is used to describe the characteristics of force, velocity, temperature, and orbit.

The general form of Navier-Stokes equations in Cartesian coordinate system is as follows:

$$
\frac{\partial \mathbf{U}}{\partial t}+\frac{\partial \mathbf{F}}{\partial x}+\frac{\partial \mathbf{G}}{\partial y}+\frac{\partial \mathbf{H}}{\partial z}=\mathbf{J},
$$

where $x, y$, and $z$ are Cartesian coordinates, $\mathbf{U}$ is the flux of conserved variables, and fluxes $\mathbf{F}, \mathbf{G}$, and $\mathbf{H}$ and source term $\mathrm{J}$ are multidimensional vectors. 


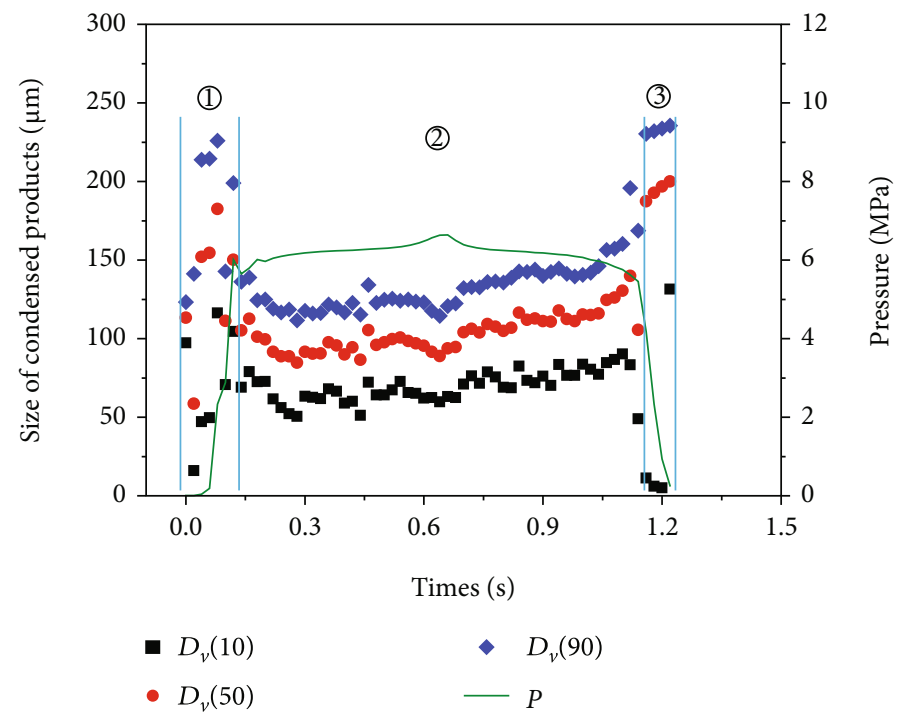

FIGURE 6: Size distribution of condensed products and pressure in the chamber.

TABle 3: Mean size, across the size distribution, $D_{v}(50)$, at different combustion stages.

\begin{tabular}{lccc}
\hline Stage & $D_{v}(50)(\mu \mathrm{m})$ & Standard deviation $\sigma$ & $d_{\max }(\mu \mathrm{m})$ \\
\hline 1 & 132 & 41 & 182 \\
2 & 104 & 12 & 140 \\
3 & 176 & 40 & 200 \\
\hline
\end{tabular}

In the Lagrange coordinate system, the trajectory of particles can be obtained by solving the force balance equation on the surface of particles:

$$
\begin{gathered}
\frac{d x_{p}}{d t}=u_{p}, \\
\frac{d u_{p}}{d t}=F_{D}\left(u-u_{p}\right)+\frac{g_{x}\left(\rho_{p}-\rho\right)}{\rho_{p}}+F_{x},
\end{gathered}
$$

where $x_{p}$ and $u_{p}$ are the displacement and velocity of particles, $u$ and $\rho$ are the displacement and velocity of gas, and $F_{D}\left(u-u_{p}\right)$ and $F_{x}$ are the resistance and residual force on per unit mass of particle.

3.2. Calculation Model and Boundary Conditions. Based on the online detection system of condensed products in plume, a two-dimensional axisymmetric numerical model is established (shown in Figure 5(a)), which shows that the total length of the outflow field is 53 times the radius of the nozzle outlet and the width is 10 times of the nozzle outlet radius, so as to overcome the influence of the boundary on the main flow area. Because the calculation domain consists of gas jet, particle flow, and complex shock structure, the calculation domain is divided into nozzle domain and flow field, and grid is generated, respectively, as well. The grid is encrypted on the wall, nozzle throat, and core area of jet. The grid division is shown in Figure 5(b).

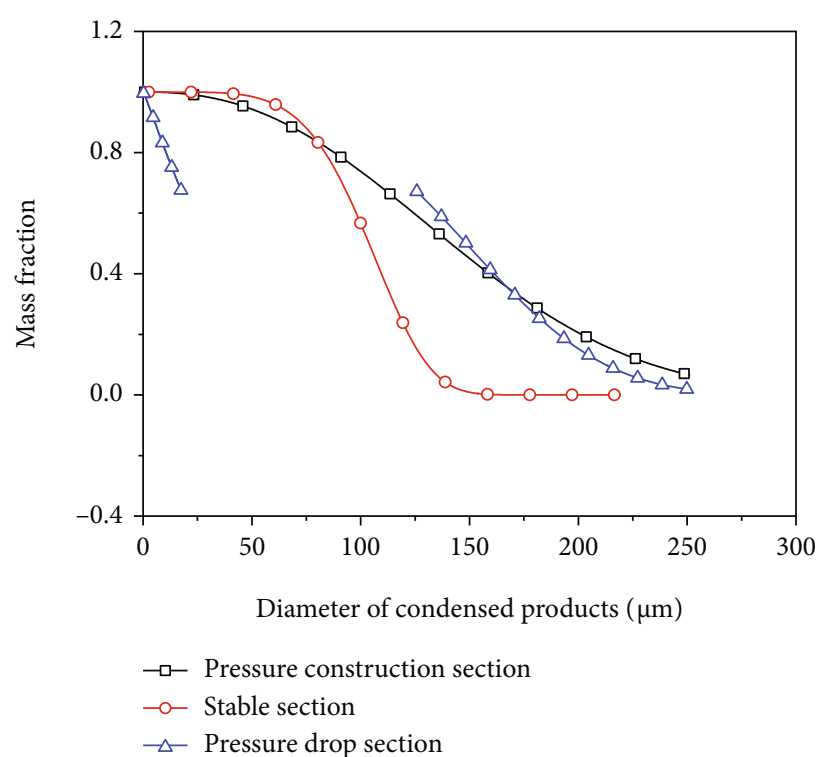

FIgURE 7: The R-R distribution of condensed products during the combustion.

TABLE 4: The R-R distribution parameters of condensed products during the combustion.

\begin{tabular}{lcccc}
\hline Stage & $d_{\min }(\mu \mathrm{m})$ & $d_{\max }(\mu \mathrm{m})$ & $D_{v}(50)(\mu \mathrm{m})$ & $n$ \\
\hline 1 & 0.8 & 251 & 165 & 2.4 \\
2 & 3 & 219 & 111 & 5.2 \\
& 0.3 & 18 & 40 & 1.1 \\
3 & 126 & 251 & 166 & 3.4 \\
\hline
\end{tabular}

The pressure inlet is used as the boundary condition at the nozzle inlet, the inlet pressure is the design pressure of the test SRM $\left(P_{\text {in }}=6 \mathrm{MPa}\right)$, the pressure outlet is used as condition of the boundary of the calculation domain $\left(P_{\text {out }}=1 \mathrm{~atm}, T_{\text {out }}=300 \mathrm{~K}\right)$, and the minimum free energy 
TABLE 5: Parameters of different conditions in simulation.

\begin{tabular}{|c|c|c|c|c|}
\hline Parameters & Pure gas phase & Stage 1 & Stage 2 & Stage 3 \\
\hline Temperature (K) & 3510 & 3510 & 3510 & 3510 \\
\hline Pressure (MPa) & 6 & 6 & 6 & 6 \\
\hline$n$ in the R-R equation & - & 2.38 & 5.23 & $1.12 / 3.35$ \\
\hline Density of particles $\left(\mathrm{kg} / \mathrm{m}^{3}\right)$ [27] & - & 4004.8 & 4004.8 & 4004.8 \\
\hline Mole fraction of $\mathrm{Al}_{2} \mathrm{O}_{3}(\%)$ & 0 & 8 & 8 & 8 \\
\hline
\end{tabular}

method is applied to calculate the gas performance parameters, shown in Table 2. The size distribution of the particles was measured by the online detection system.

\section{Results and Discussion}

4.1. Characteristics of Size Distribution of Condensed Products. The average size, $D_{v}(10), D_{v}(50)$, and $D_{v}(90)$, of condensed products in the plume and the pressure in the chamber pressure is shown in Figure 6. It is found that the same trend is observed in the average size of $D_{v}(10), D_{v}(50$ ), and $D_{v}(90)$. According to the pressure distribution in the combustion chamber, the engine working process can be divided into three stages: pressure construction section (stage 1 ), stable section (stage 2), and pressure drop section (stage 3 ). In stages 1 and 3 , the size of condensed products is widely distributed at $0-250 \mu \mathrm{m}$, and there is no obvious rule between average size and combustion time. In stage 2 , the distribution range of condensed products was significantly reduced, ranging from 45 to $200 \mu \mathrm{m}$. In order to further explore the distribution characteristics of condensed products, quantitative analysis of size distribution in different stages is carried out in Table 3). Compared with that in stages 1 and 3, the standard deviation of the particle size and the maximum particle size of condensed products are significantly reduced in stage 2 , indicating that the dispersion of size distribution of condensed products in stage 2 is lower. The results show that the standard deviation, $\sigma$, is reduced from 40.72 and 39.95 to 12.16 , the mean size, $D_{v}(50)$, is reduced from $131.77 \mu \mathrm{m}$ and $176.48 \mu \mathrm{m}$ to $103.66 \mu \mathrm{m}$, and the maximum size, $d_{\max }$, is reduced from $182.49 \mu \mathrm{m}$ and $199.97 \mu \mathrm{m}$ to $139.95 \mu \mathrm{m}$. In addition, it is found that the source of condensed products in stage 2 is from both combustion products of black powder and propellant, and the main products are from the combustion of the black powder according to the size distribution in stage 1 . So the sudden change of pressure and temperature in combustion chamber and the random combustion characteristics of black powder mainly affect the size distribution in this stage.

The size distribution of condensed products in the plume can be measured in real time by the online detection system established in Section 2.2. The change of the mean size with the pressure and ignition time is displayed in stage 1 ; the distribution of mean size in stage 2 shows that the particle size of condensed product changes with stable pressure; the results in stage 2 show that the decrease of pressure and temperature drop have an effect on size distribution of condensed products.

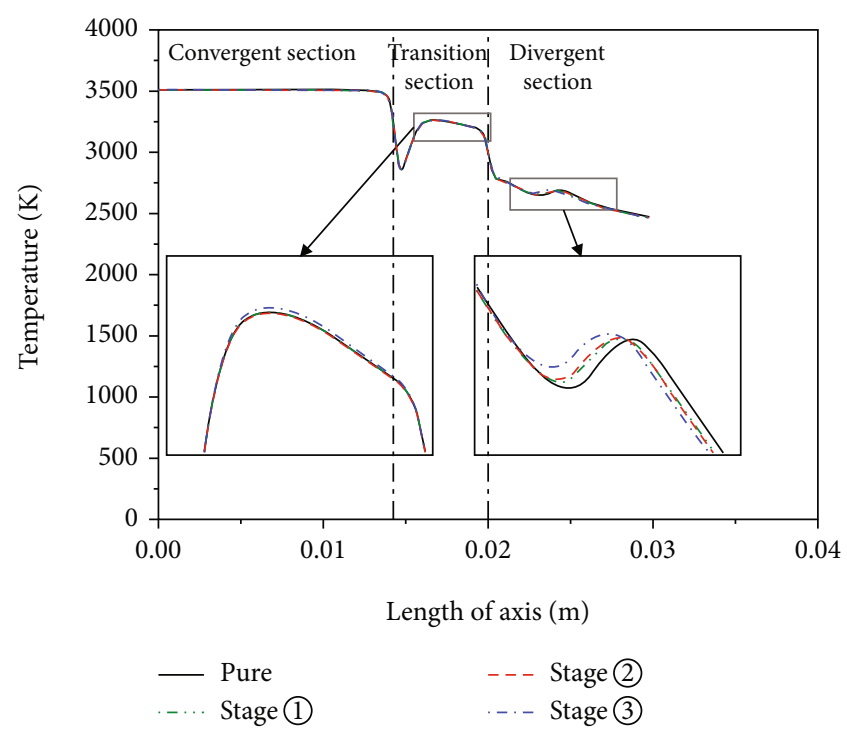

Figure 8: Temperature distribution on the wall of nozzle.

4.2. $R-R$ Distribution at Typical Time in Different Stages. The Rosin-Rammler (R-R) distribution function can describe the size distribution in the simulation of the gas-solid two-phase flow [24-26]. The expression of the R-R distribution function is described as follows:

$$
Y_{d}=e^{-\left(d / d_{m}\right)^{n}}
$$

where $Y_{d}$ is the cumulative distribution of particle mass fraction, $d_{m}$ is the mean size of the particles, and $n$ is the distribution index.

The size of condensed products input during simulation adopts the mean size of the midpoints at each stage of the combustion process. The mean size, $D_{v}(50)$, of the R-R distribution of condensed products at stage 1 is $164.91 \mu \mathrm{m}$, and the distribution index was 2.38; the mean size, $D_{v}(50)$, of the R-R distribution of condensed products at stage 2 is $111.38 \mu \mathrm{m}$, and the distribution index was 5.23. However, the mean size, $D_{v}(50)$, of the R-R distribution of condensed products at stage 3 can be divided into two phases as shown in Figure 7, so the R-R distribution function needs to be calculated by two stages. The mean size, $D_{v}(50)$, of the first peak $\mathrm{R}-\mathrm{R}$ distribution is $40.41 \mu \mathrm{m}$, and the distribution index was 1.12; the mean size, $D_{v}(50)$, of the second peak R-R distribution is $165.64 \mu \mathrm{m}$, and the distribution index was 3.35. The R$\mathrm{R}$ distribution of the particle size of condensed products at the above three typical moments is shown in Figure 7, and the R-R distribution parameters are shown in Table 4. 


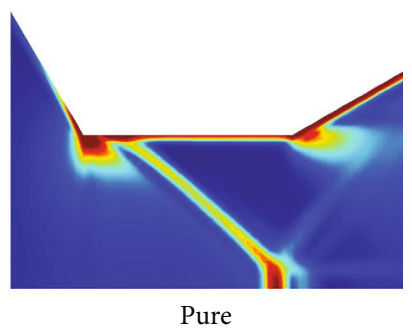

(a)

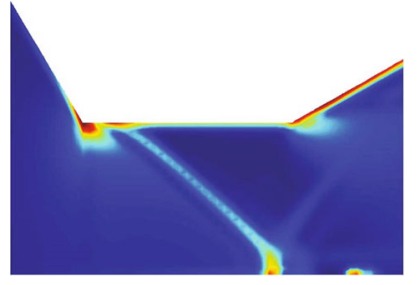

Stage (1)

(b)

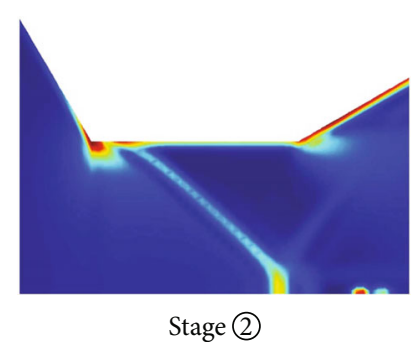

(c)

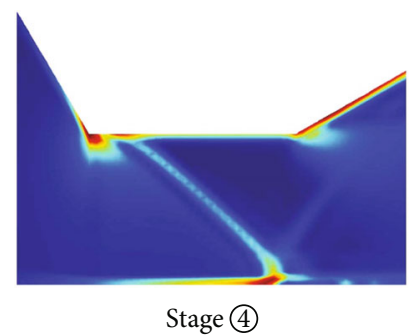

(d)

Figure 9: Shock wave structure in the transition section of nozzle. (a) Pure. (b) Stage 1. (c) Stage 2. (d) Stage 3.

4.3. Analysis of Flow in Nozzle. Based on the R-R size distribution of condensed products at three typical times obtained from the experiment in Figure 7, the influence of solid particles with mixed diameters on the characteristics of flow field is simulated, and the detailed conditions are shown in Table 5.

The temperature distribution of nozzle wall under stages 1 to 3 and pure gas phase condition is shown in Figure 8. In the convergent section of the nozzle, the temperature distribution in three stages is consistent with that of the pure gas phase, except that the temperature on the wall at the end of the convergent section decreases, and the temperature at other positions is consistent with the inlet temperature of the nozzle $(3510 \mathrm{~K})$. In the transition section of nozzle, the distribution of temperature is almost the same as that in pure gas phase. Under the influence of oblique shock wave, the temperature has experienced a significant decrease of $675 \mathrm{~K}$. Then, with the influence of shock wave gradually weakened, the nozzle wall temperature rises and remains stable. The maximum temperature on the wall of nozzle is $3267 \mathrm{~K}$ in stage 3 , which is slightly higher than that in stage 1 , stage 2 , and the pure gas phase condition. However, due to the small difference between these four conditions, it can be considered that the different condensed products have little effect on the wall temperature of nozzle in transition section, which is mainly because the condensed products do not significantly change the structure of shock wave in nozzle transition section, as shown in Figure 9. In the divergent section of the nozzle, the temperature change of the nozzle wall is closer to the transition section due to the addition of condensed products; however, the condensed products can hardly affect the temperature distribution of the nozzle wall.

The Mach number at the outlet of nozzle is shown in Figure 10 under four conditions. Near the axis (radial position $=0 \mathrm{~m}$ ), the Mach number under pure gas phase condition is 2.48 , and the Mach number is decreased as the existence of condensed products in stages 1 to 3 . The Mach number at the central axis of stage 3 decreases to 1.89 , in which the Mach number drops the most. The results show that the existence of particles will cause velocity lag in the nozzle, and the larger the particle size is, the more obvious the lag effect is. However, the lag effect is not obvious in the nozzle.

4.4. Analysis of Temperature in Flow Field. The temperature of plume in flow field in stages 1 to 3 and pure gas condition is shown in Figure 11. At the outlet of nozzle

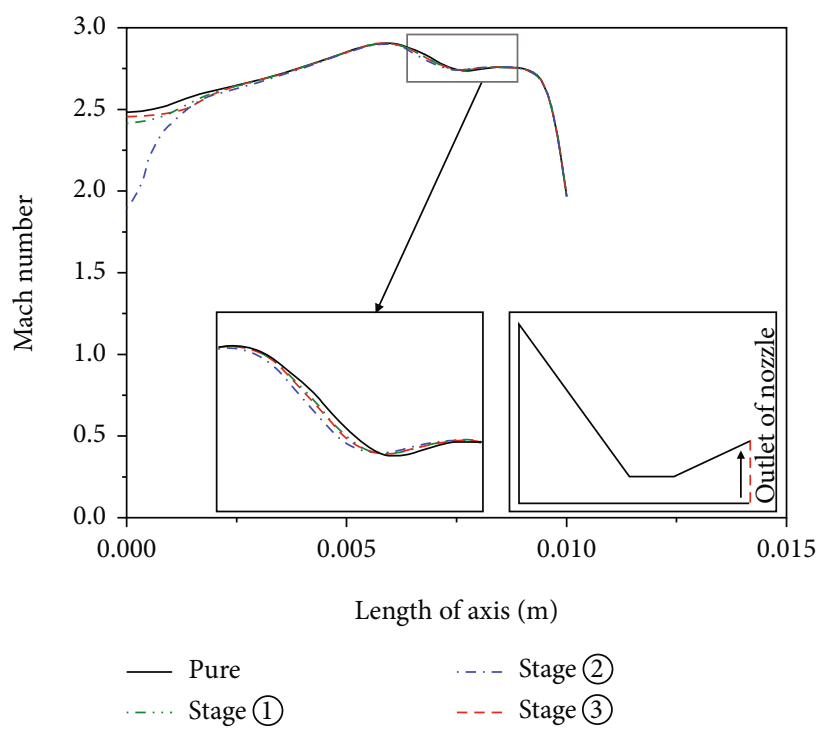

FIgURE 10: The Mach number at outlet of nozzle.

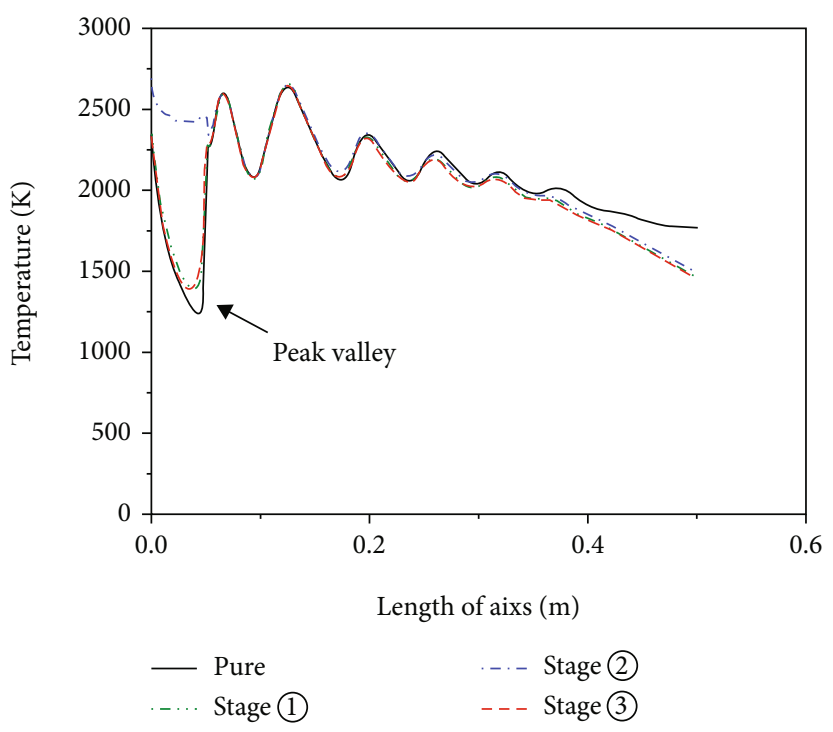

Figure 11: Temperature on the axis of the plume.

(axial position $=0 \mathrm{~m}$ ), the temperature under pure gas condition is $2307 \mathrm{~K}$, while the temperature under stage 1 and stage 2 is $2345 \mathrm{~K}$ and $2322 \mathrm{~K}$, respectively, and it even rises to $2686 \mathrm{~K}$ in stage 3 . As for the existence of condensed 


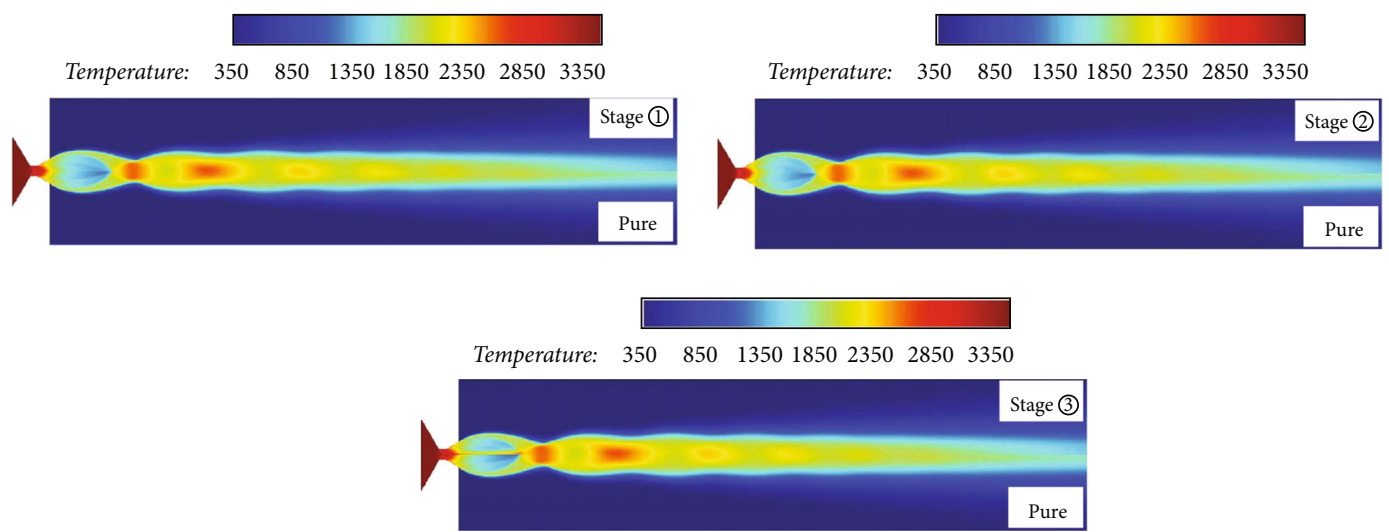

Figure 12: Temperature of the plume in stages 1-3.

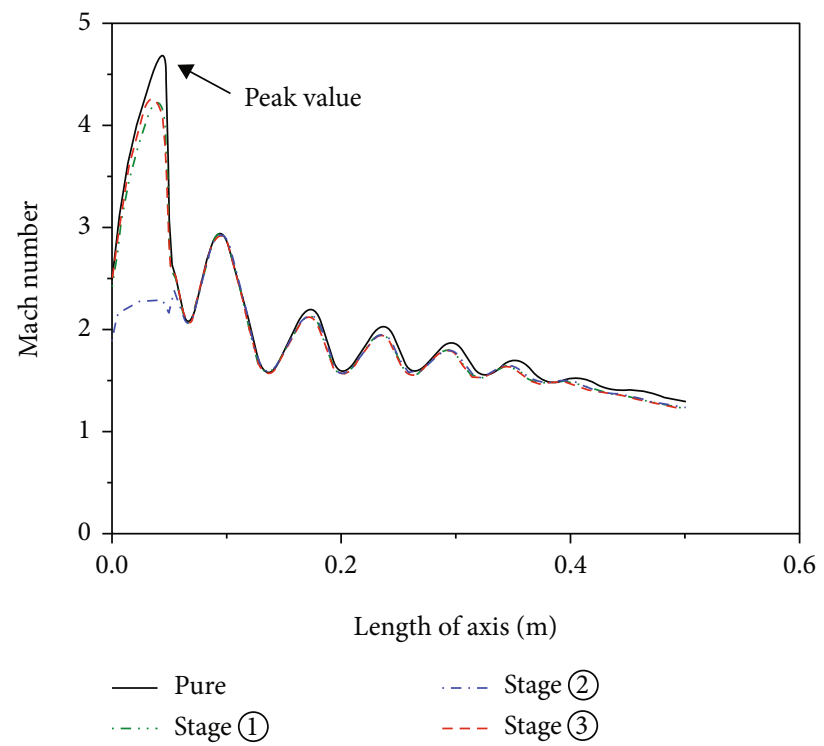

FIgURE 13: The Mach number on the axis of the plume.

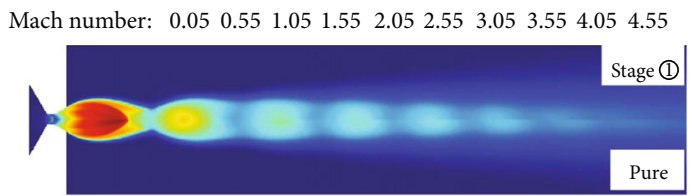

Mach number: $0.05 \quad 0.55 \quad 1.05 \quad 1.55 \quad 2.052 .55 \quad 3.05 \quad 3.55 \quad 4.05 \quad 4.55$

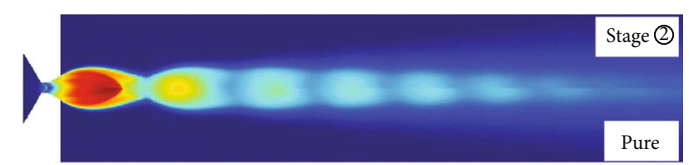

Mach number: $\quad 0.05 \quad 0.55 \quad 1.05 \quad 1.55 \quad 2.052 .55 \quad 3.05 \quad 3.55 \quad 4.05 \quad 4.55$

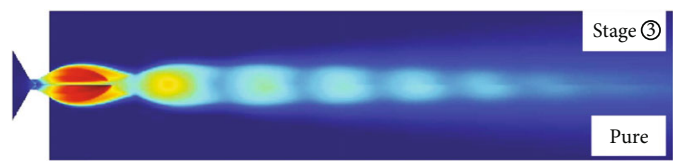

Figure 14: The Mach number of the plume in stages 1-3.

products in stages 1 to 3 , the distribution trend of temperature in the plume is consistent with that of the pure gas phase, but the temperature of plume increases, and the change of temperature is the most severe in stage 3 . The temperature oscillates irregularly under the influence of the shock wave and reaches the peak valley at the position of the first Mach disk, and the variation range of the peak valley temperature is very small due to the influence of 
condensed products. The condensed products have the greatest influence on the temperature in stage 3, and with the increase of the size of condensed particles in the plume, the temperature in the plume is the higher. Before axial position $=0.055 \mathrm{~m}$, the shock wave structure in the flow field is obviously changed due to condensed products in stage 3 , resulting in no obvious temperature peak valley in this area and a large difference of temperature between other stages. After axial position $=0.055 \mathrm{~m}$, the gas temperature oscillates irregularly under the influence of shock wave system, and the change trend is the same as other conditions. This shows that the effect of condensed products on the temperature of plume mainly occurs before the first Mach disk. The temperature distribution in all four stages is shown in Figure 12, and it can be found that the effect of condensed products on plume is the most significant in stage 3 .

4.5. Analysis of the Mach Number in Plume. The Mach number in the plume is shown in Figure 13 under the conditions of stages 1 to 3 and pure gas phase. At the outlet of nozzle (axial position $=0 \mathrm{~m}$ ), the Mach number is 2.48 under the pure gas phase condition, and the Mach numbers in stages 1 and 2 are 2.42 and 2.46, respectively. However, the Mach number in stage 3 is only 1.89, and the Mach numbers in all three stages with the addition of condensed products are less than those in pure gas phase condition. Moreover, the velocity lag effect caused by condensed products is the most obvious in stage 3, which leads to the largest reduction of the Mach number. The results show that the distribution trend of Mach number is consistent with that of pure gas phase in stages 1 and 2 , which is the same trend as that of temperature. The Mach number oscillates irregularly under the influence of shock wave and reaches the peak at the position of the first Mach disk. The peak value of the Mach number in pure gas phase is 4.69, and the peak value of Mach number is 4.23 and 4.29 in stages 1 and 2 , respectively. Therefore, the influence of condensed products on the Mach number mainly occurs before the first Mach disk. The difference of the Mach number distribution in the plume between stages 1 and 3 and pure gas phase condition is shown in Figure 14, and it can be found that the effect of condensed products on plume is the most significant in stage 3 due to the change of the first Mach disk.

\section{Conclusion}

In this paper, the experimental system is presented to obtain the real-time distribution of condensed products in the plume and numerical methods combined with tested results are applied to simulate the characteristics of flow field. There are obvious velocity lag and temperature lag in the presence of condensed products, and the lag in plume is the most significant in the pressure drop section. The real-time distribution of condensed products obtained in the experiment can provide data support for the future numerical simulation.

\section{Data Availability}

The data used to support the findings of this study are included within the article.

\section{Conflicts of Interest}

The authors declare that they have no conflicts of interest.

\section{References}

[1] P. Liu, J. Bai, X. Yang, and Z. Zhao, "Collection and analysis of condensate particles in solid rocket engine combustion chamber," Solid State Rocket Technology, vol. 31, no. 5, pp. 461-463, 2008.

[2] H. Zhang, D. Ye, X. Hou, and B. Gao, "Experimental study on condensed phase particle distribution in combustion field of aluminum-containing composite propellant," Solid State Rocket Technology, vol. 24, no. 1, pp. 24-27, 2001.

[3] N. Wang, C. Long, C. Zhao, and S. Li, "Experimental study on particle distribution in solid rocket combustion chamber," Journal of Propulsion Technology, vol. 16, no. 4, pp. 24-27, 1995.

[4] B. Jin, P. Liu, X. Du, X. Liu, and Y. Guan, "Effect of particle size of aluminum powder on distributed combustion response and particle damping characteristics in composite propellant," Journal of Propulsion Technology, vol. 35, no. 12, pp. 17011706, 2014.

[5] D. L. Hovland, Particle Sizing in Solid Rocket Motors, Naval Postgraduate School, California, 1989.

[6] M. W. Beckstead, R. S. Richards, and B. S. Brewster, "Distributed combustion effects on particle damping," AIAA Journal, vol. 22, no. 3, pp. 383-387, 1984.

[7] M. W. Beckstead, "Correlating aluminum burning times," Combustion, Explosion, and Shock Wave, vol. 41, no. 5, pp. 533-546, 2005.

[8] S. E. Olsen and M. W. Beckstead, "Burn time measurements of single aluminum particles in steam and $\mathrm{CO} 2$ mixtures," Journal of Propulsion and Power, vol. 12, no. 4, pp. 662-671, 2011.

[9] V. A. Babuk, V. A. Vasilyev, A. Glebov et al., "Combustion mechanisms of AN-based aluminized solid rocket propellants," in Proceeding of 9th International Workshop on Combustion and Propulsion: Novel Energetic Materials and Application, IWCP, At Lerici, SP, Italy, 2004.

[10] J. C. Melcher, H. Krier, and R. L. Burton, "Burning aluminum particles inside a laboratory-scale solid rocket motor," Journal of Propulsion and Power, vol. 18, no. 3, pp. 631-640, 2002.

[11] V. E. Zarko and O. G. Glotov, "Formation of Al oxide particles in combustion of aluminized condensed systems," Science and Technology of Energetic Materials, vol. 74, no. 6, pp. 139-143, 2013.

[12] W. Ao, X. Liu, H. Rezaiguia, H. Liu, Z. Wang, and P. Liu, “Aluminum agglomeration involving the second mergence of agglomerates on the solid propellants burning surface: experiments and modeling," Acta Astronautica, vol. 136, pp. 219229, 2017.

[13] H. Liu, W. Ao, P. Liu et al., "Experimental investigation on the condensed combustion products of aluminized GAP-based propellants," Aerospace Science and Technology, vol. 97, p. 105595, 2020.

[14] D. L. LT, "Burning of aluminized solid rocket propellants: from micrometric to nanometric fuel size," in International Autumn Seminar on Propellants, pp. 277-289, Explosives and Pyrotechnics. Science Press, China, 2007.

[15] D. Laredo, J. D. McCrorie, J. K. Vaughn, and D. W. Netzer, "Motor and plume particle size measurements in solid 
propellant micromotors," Journal of Propulsion and Power, vol. 10, no. 3, pp. 410-418, 1994.

[16] Z. Haiqing, Numerical Simulation of Ignition Stage and Experimental Investigation of Exhaust Plume on Solid Propellant Impulsive Microthruster, Beijing Institute of Technology, Beijing, 2005.

[17] W. Wang, L. Jianming, R. Yang, Z. Liu, and S. P. Li, "Influence of organic fluorine-contained additives on condensed combustion products of aluminized polyether propellants," Journal of Acta Armament, vol. 38, no. 4, pp. 704-710, 2017.

[18] R. A. Reed and V. S. Calia, "Review of aluminum oxide rocket exhaust particles," in 28th Thermophysics Conference, Fluid Dynamics and Co-located Conferences, Orlando, FL, US, 1993AIAA.

[19] W. Wang, Research on Infrared Radiation Signature of Exhaust Plume from Solid Rocket Motor, Beijing Institute of Technology, Beijing, 2005.

[20] C. Jun and Y. Zheng, "Laser scattering theory and its application in metrology testing," Laser Technology, vol. 20, no. 6, pp. 359-365, 1996.

[21] M. Born and E. Wolf, Principles of Optics, vol. Volume 1, Science Press, Shanghai, 1981.

[22] X. Kong, D. Jie, and J. Yongming, "Key technologies and research progress of laser particle size analyzer," Petrochemical Technology, vol. 26, no. 3, pp. 187-187, 2019.

[23] Z. Youyu, "Discussion on the precision of the application of Mie theory," Journal of Acta Armamentarii, vol. 11, no. 3, pp. 59-66, 1990.

[24] Z. He, Y. Gao, and G. Xuan, "Numerical simulation of 3-D two-phase flow in solid rocket motor with star grain," Journal of Propulsion Technology, vol. 26, no. 3, pp. 354-357, 2005.

[25] H. Feng, X. Zhu, B. Zhang et al., "Visualization of two-phase reacting flow behavior in a gas-liquid-solid microreactor," Reaction Chemistry \& Engineering, vol. 4, no. 4, pp. 715-723, 2019.

[26] D. Liyan, "Research on Rosin-Rammler particle size distribution function," Industrial Safety and Environmental Protection, vol. 3, pp. 15-17, 2000.

[27] O. B. Kovalev, "Prediction of the size of aluminum-oxide particles in exhaust plumes of solid rocket motors [J]," Combustion, Explosion and Shock Waves, vol. 38, no. 5, pp. 535-546, 2002. 